\title{
Mechanical Versus Manual Chest Compression: A Retrospective- Cohort in Out-of-Hospital Cardiac Arrest
}

\author{
Alp Şener ${ }^{1,2},[M D]$ \\ ORCID: 0000-0002-0583-2936
}

Gül Pamukçu Günaydın',2, [MD]
ORCID: 0000-0001-8531-4591

Fatih Tanrıverdi ${ }^{1,2}$, [MD]

ORCID: 0000-0001-9959-5769
A short summary of this article, presented in 15th Turkish Emergency Medicine Congress, in AntalyaTurkey in 2019, Nov 21-24th as oral presentation.

'Yıldırım Beyazıt University, Faculty of Medicine, Department of Emergency Medicine, Ankara, Turkey.

${ }^{2}$ Ministry of Health, Ankara City Hospital, Department of Emergency Medicine, Ankara, Turkey.

Corresponding Author: Alp Şener Ankara City Hospital, Department of Emergency Medicine, Bilkent / Ankara / Turkey.

E-mail: alpsener@gmail.com

https://doi.org/10.32552/2021.ActaMedica.657

\section{n ABSTRACT Con}

Objective: In cardiac arrest cases, high quality cardiopulmonary resuscitation and effective chest compression are vital issues in improving survival with good neurological outcomes. In this study, we investigated the effect of mechanical chest compression devices on 30day survival in out-of-hospital cardiac arrest.

Materials and Methods: This retrospective case-control study was performed on patients who were over 18 years of age and admitted to the emergency department for cardiac arrest between January 1, 2016 and January 15, 2018. Manual chest compression was performed to the patients before January 15, 2017, and mechanical chest compression was performed after this date. Return of spontaneous circulation, hospital discharge, and 30-day survival rates were compared between the groups of patients in terms of chest compression type. In this study, the LUCAS-2 model piston-based mechanical chest compression device was used for mechanical chest compressions.

Results: The rate of return of spontaneous circulation was significantly lower in the mechanical chest compression group $(11.1 \%$ vs $33.1 \%$; $p<0.001)$. The 30-day survival rate was higher in the manual chest compression group (6.8\% vs $3.7 \%)$; however, this difference was not statistically significant $(p=0.542)$. Furthermore, 30-day survival was $0 \%$ in the trauma group and $0.6 \%$ in the patient group who underwent cardiopulmonary resuscitation for over 20 minutes.

Conclusion: It can be seen that the effect of mechanical chest compression on survival is controversial; studies on this issue should continue and, furthermore, studies on the contribution of mechanical chest compression on labor loss should be conducted.

Keywords: Cardiopulmonary resuscitation, chest compression, manual, mechanical

Received: 27 July 2021, Accepted: 6 October 2021,

Published online: 20 November 2021 


\section{INTRODUCTION}

Despite various studies and developments in cardiopulmonary resuscitation (CPR), out-ofhospital cardiac arrest (OHCA) still remains an important public health problem. Survival and hospital discharge rates have been reported between $5 \%$ and $20 \%$ in cardiac arrest [1-3]. The most important factor in improving survival is effective, high-quality, and on-time CPR [1]. However, chest compressions performed by health care providers often remain shallow, with long hands-off time; this also adversely affects the survival [4].

Chest compression devices are capable of continuous chest compression with appropriate rate and depth. Although there are many devices in the field, they are generally evaluated in two groups according to the mechanism they employ; load-distributing band or piston-based devices [5]. The Lund University Cardiac Assist System-2 (LUCAS-2), which is used on patients undergoing mechanical chest compression in this study, is able to perform chest compressions at a rate of 4 to $5 \mathrm{~cm}$ and 100 times per minute continuously and active decompression. We hypothesized that resuscitation success may improve with mechanical chest compression via LUCAS-2.

The mechanical chest compression device is actively used in all cardiac arrest patients in our clinic. We think that it especially prevents labor loss based on our personal experience; however, the debate about its effect on survival remains valid in the emergency department (ED) settings. Numerous studies have evaluated the efficacy of LUCAS-2 and similar devices [1,3,4,6-12]. There is no clear data on the effect of mechanical chest compression devices on 30-day survival in the literature. In this study, we compared LUCAS-2 with manual chest compression on ROSC, 30-day survival, and hospital discharge parameters in outof-hospital cardiac arrest cases based on a 1-year history of mechanical compression use.

\section{MATERIALS and METHODS}

This study was performed retrospectively in the ED of an advanced training and research hospital between January 1, 2016 and January 15, 2018. Ethical approval for this study was obtained from the local ethics committee in June, 2018. Informed consent was not obtained from the patients due to retrospective design. The study was conducted in accordance with the principles of the World Medical Association (WMA) Declaration of Helsinki.

In this study, the data of OHCA cases who underwent $C P R$ in the ED were analyzed retrospectively to compare the effectiveness of manual and mechanical chest compressions. Patients who had cardiac arrest outside the hospital and who were admitted to the ED with CPR were included in the study. Only the CPRs performed after the patient entered the emergency room were evaluated and analyzed. As of January 15, 2017, a mechanical chest compression device was included in the inventory of the ED where the study was conducted. As of this date, all cardiac arrest cases were managed with using this device. Before January 15, 2017, all patients underwent manual chest compression. Resuscitation by emergency medical system stuff (EMS) at the scene or during transport (out of hospital) was not included in the analysis. The patient's admission to the ED was accepted as minute- 0 , and data were collected and analyzed. Patients under 18 years of age were excluded. In addition, the patients were excluded from the study when the device could not be used due to a very small or a large body size.

In the study, chest compression in the mechanical CPR group was performed with the LUCAS ${ }^{\mathrm{TM}} 2$ Chest Compression System (LUCAS). LUCAS is a portable device designed to reduce problems encountered during manual chest compression and is capable of performing standard, continuous chest compression, which will collapse the chest by 4 to $5 \mathrm{~cm}$ and make at least 100 compressions per minute. In addition, this device provides an active decompression with a suction cap.

The primary outcomes of the study were 30-day survival, the return of spontaneous circulation (ROSC), and hospital discharge. ROSC expression was used for cases where the presence of the pulse was maintained for at least 5 minutes after the return. Initial rhythm was defined as the first arrest rhythm detected in emergency medicine. Data were collected from the hospital information management system and examination forms of patients during the 3-month study period. 


\section{Statistical Analysis}

Data were analyzed with IBM SPSS for Windows 15.0 Package Program. ROSC, hospital discharge, and 30-day survival were compared between the groups of patients who underwent manual CPR and mechanical CPR. Frequency analyses of categorical variables were performed with Chi-Square tests. Normality analysis of continuous data was performed using the Shapiro-Wilk test. The Mann Whitney-U test was used to compare continuous and non-normally distributed data between two independent groups. The $p<0.05$ level was used for statistical significance.

\section{RESULTS}

In this study, 214 patients over 18 years of age were included. Among these patients, 133 (62.1\%) who underwent manual chest compression and 81 (37.9\%) patients undergoing mechanical chest compression exhibited a homogenous distribution in terms of age and sex (Table 1). Among the comorbid diseases, only pulmonary thromboembolism was significantly higher in the mechanical compression group (3.7\% and 0.0\%) (Table 1). In terms of seasonal distribution, more cases were seen in the autumn season in the mechanical CPR group. There was no statistically significant difference between admission time (hour shift), traumatic arrest rates, initial rhythms, and CPR duration time (Table 1).

ROSC was significantly lower in the mechanical compression group (11.1\% vs $33.1 \% ; p<0.001)$. All discharged patients had also 30-day survival. Therefore, discharge and 30-day survival were used in the similar meaning in this study. The rate of 30day survival was higher in the manual compression group (6.8\% vs $3.7 \%)$, but this difference was not statistically significant ( $p=0.542$ ) (Table 2 ).

ROSC and 30-day survival rates were statistically similar between genders ( $p=0.096$ and 0.235 , respectively). 30-day survival rate was significantly higher in the group under 65 years of age $(p=$ $0.021)$. ROSC was significantly lower in traumatic arrest cases $(p=0.004)$, there were no surviving patients in this traumatic cardiac arrest group. Both ROSC and 30-day survival rates were significantly higher in the ventricular fibrillation and pulseless ventricular tachycardia (VF/pulseless VT) group compared to the asystole and pulseless electrical activity (Asystole / PEA) group (Table 3). Both the ROSC and the 30-day survival were significantly lower in the group with a CPR duration time of over 20 min compared to others ( $p<0.001$; Table 3 ).

\section{DISCUSSION}

The American Heart Association (AHA) resuscitation guidelines focus on early recognition of cardiac arrest, early activation of the emergency medical services, early onset of CPR with effective chest compression, and rapid defibrillation to improve survival in patients with cardiac arrest [13-15]. In this way, providers should apply effective chest compression to each patient regardless of patient characteristics, provider ability, or accessible equipment status [14].

In this study, the effectiveness of manual and mechanical chest compression was compared in out-of-hospital cardiac arrest patients. The mechanical chest compression was not superior to the manual chest compression in terms of ROSC, 30-day survival, or hospital discharge. However, results revealed that better ROSC rates were obtained in the manual chest compression group (Table-2). It is noteworthy that in the trauma group and in the group with a CPR duration of more than 20 minutes, survival was close to zero. As expected, in the geriatric group and asystole/NEA group, the ROSC and survival rates were worse (Table-3).

In the literature, mixed results have been obtained in terms of mechanical chest compression devices. In 2018, Wang and Brooks published a review that included 11 randomized trials and 12,944 cases in total [16]. In particular, three large-scale studies conducted analyses on hospital discharge and survival in an OHCA group $[7,8,17]$. In Hallstrom et al., mechanical chest compression was reported to have a poor effect on survival [17]. Two subsequent studies state no difference in terms of survival to hospital discharge and good neurological outcomes. In addition, there was no evidence to show a difference in 30 -day survival $[7,8]$. In the Perkins et al study mentioned, although there was no difference in terms of 30-day and 3-month survival, positive neurological outcome rates were lower in the mechanical chest compression group in the 3-month period [18]. Similar results were obtained in our study; however, our study did not include data relating to neurological outcomes. 
Table 1. Demographic features

\begin{tabular}{|c|c|c|c|c|}
\hline & & MANUAL VS MEC & NICAL CPR- $\mathrm{n}(\%)$ & \\
\hline & & $\begin{array}{c}\text { Manuel } \\
133(\% 62.1)\end{array}$ & $\begin{array}{l}\text { Mechanical } \\
81(\% 37.9)\end{array}$ & P-value \\
\hline Age- median (min-m & & $65(18-103 / 30)$ & $66(15-100 / 23)$ & $0.959 *$ \\
\hline Gender-n (\%) & $\begin{array}{l}\text { Female } \\
\text { Male }\end{array}$ & $\begin{array}{l}42(31.6) \\
91(68.4)\end{array}$ & $\begin{array}{l}27(33.3) \\
54(66.7)\end{array}$ & $0.790 \dagger$ \\
\hline Age (groups) - n (\%) & $\begin{array}{l}\text { Young }(<65) \\
\text { Young-old }(65-74) \\
\text { Middle-old }(75-84) \\
\text { Oldest-old }(\geq 85)\end{array}$ & $\begin{array}{l}66(49.6) \\
22(16.5) \\
23(17.3) \\
22(16.5)\end{array}$ & $\begin{array}{l}38(46.9) \\
15(18.5) \\
16(19.8) \\
12(14.8)\end{array}$ & $0.929+$ \\
\hline CAD- n (\%) & & $20(15.0)$ & $11(13.6)$ & $0.769+$ \\
\hline DM- n (\%) & & $18(13.5)$ & $9(11.1)$ & $0.605+$ \\
\hline HT- n (\%) & & $16(12.0)$ & $7(8.6)$ & $0.438+$ \\
\hline CVD- n (\%) & & $8(6.0)$ & $2(2.5)$ & $0.233+$ \\
\hline COPD- n (\%) & & $8(6.0)$ & $5(6.2)$ & $0.963+$ \\
\hline PTE- n (\%) & & $0(0.0)$ & $3(3.7)$ & $0.025+$ \\
\hline Malignancy- $\mathrm{n}(\%)$ & & $8(6.0)$ & $6(7.4)$ & $0.690+$ \\
\hline CKD- n (\%) & & $4(3.0)$ & $2(2.5)$ & $0.817 \dagger$ \\
\hline Season- $\mathrm{n}(\%) \neq$ & $\begin{array}{l}\text { Spring } \\
\text { Summer } \\
\text { Autumn } \\
\text { Winter }\end{array}$ & $\begin{array}{l}43(32.3) \\
29(21.8) \\
23(17.3) \\
38(28.6)\end{array}$ & $\begin{array}{l}23(28.4) \\
15(18.5) \\
28(34.6) \\
15(18.5)\end{array}$ & $0.031 \dagger$ \\
\hline Shift- n (\%) & $\begin{array}{l}08-16 \\
16-24 \\
24-08\end{array}$ & $\begin{array}{l}63(47.4) \\
43(32.3) \\
27(20.3)\end{array}$ & $\begin{array}{l}35(43.2) \\
28(34.6) \\
18(22.2)\end{array}$ & $0.838+$ \\
\hline Trauma-n (\%) & $\begin{array}{l}\text { Atraumatic } \\
\text { Traumatic }\end{array}$ & $\begin{array}{l}113(85.0) \\
20(15.0)\end{array}$ & $\begin{array}{c}72(88.9) \\
9(11.1)\end{array}$ & $0.416+$ \\
\hline Rhythm- n (\%) & $\begin{array}{l}\text { Asystole } \\
\text { PEA } \\
\text { VF/pulseless VT }\end{array}$ & $\begin{array}{l}52(39.1) \\
63(47.4) \\
18(13.5)\end{array}$ & $\begin{array}{l}32(39.5) \\
29(35.8) \\
20(24.7)\end{array}$ & $0.078+$ \\
\hline CPR duration- media & & $45(2-100 / 35)$ & $45(2-100 / 20)$ & $0.866^{*}$ \\
\hline CPR duration- $\mathrm{n}(\%)$ & $\begin{array}{l}\leq 20 \mathrm{dk} \\
>20 \mathrm{dk}\end{array}$ & $\begin{array}{l}37(27.8) \\
96(72.2)\end{array}$ & $\begin{array}{l}14(17.3) \\
67(82.7)\end{array}$ & $0.079+$ \\
\hline
\end{tabular}

CPR: Cardiopulmonary resuscitation; IQR: Interquartile range; CAD: Coronary artery disease; DM: Diabetes mellitus; HT: Hypertension; CVD: Cerebrovascular disease; COPD: Chronic obstructive pulmonary disease; PTE: Pulmonary thromboembolism; CKD: Chronic kidney disease; PEA: Pulseless electrical activity; VF: Ventricular fibrillation; VT: Ventricular tachycardia

*Mann Whitney-U test

tPearson Chi-square test

‡Difference was originated from "Autumn" group in terms of season parameter.

High quality CPR is one of the most important factors during the transport of patients with cardiac arrest. Lyon et al suggested that there were much fewer interruptions in ambulances with mechanical compression devices compared to manual chest compression [19]. It has been suggested that mechanical devices would be useful during the transport of patients because of the safety of the providers and the potential poor quality of chest compression resulting from the movement of the ambulance $[5,19]$. On the other hand, it has been stated that the quality of CPR provided in the ED can be achieved under prehospital conditions $[20,21]$. There are also conditions, such as helicopter transport, where CPR is extremely difficult. In a simulation study, CPR criteria in helicopter environments were found to be more optimal with mechanical devices [4]. 
Table 2. Main results in the CPR groups

\begin{tabular}{|c|c|c|c|c|}
\hline & & MANUAL VS & CPR- n (\%) & \\
\hline & & $\begin{array}{c}\text { Manuel } \\
133(\% 62.1)\end{array}$ & $\begin{array}{l}\text { Mechanical } \\
81(\% 37.9)\end{array}$ & P-value \\
\hline ROSC- n (\%) & $\begin{array}{l}\text { No ROSC } \\
\text { ROSC }\end{array}$ & $\begin{array}{l}89(66.9) \\
44(33.1)\end{array}$ & $\begin{array}{l}72(88.9) \\
9(11.1)\end{array}$ & $<0.001^{*}$ \\
\hline Discharge-n (\%) & $\begin{array}{l}\text { Mortal in hospital } \\
\text { Discharge }\end{array}$ & $\begin{array}{c}124(93.2) \\
9(6.8)\end{array}$ & $\begin{array}{c}78(96.3) \\
3(3.7)\end{array}$ & $0.542 \dagger$ \\
\hline Results- n (\%) & $\begin{array}{l}\text { No ROSC } \\
\text { Mortality in } 30 \text { days } \\
30 \text { days survival } \\
\text { Discharge }\end{array}$ & $\begin{array}{c}89(66.9) \\
35(26.3) \\
9(6.8) \\
9(6.8)\end{array}$ & $\begin{array}{l}72(88.9) \\
6(7.4) \\
3(3.7) \\
3(3.7)\end{array}$ & \\
\hline
\end{tabular}

CPR: Cardiopulmonary resuscitation; ROSC: Return of spontaneous circulation

*Pearson Chi-square

tFisher's Exact test

Table 3. Main results in subgroups

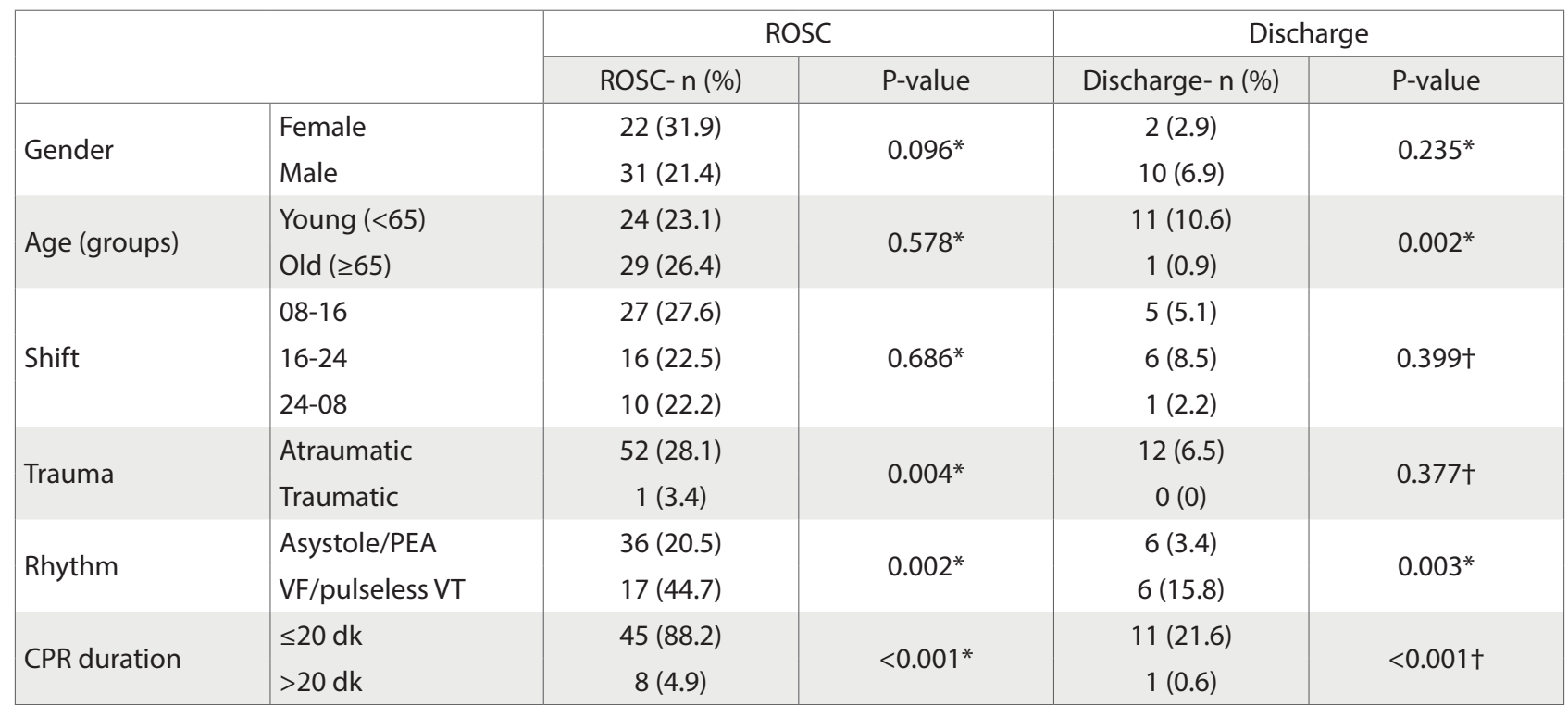

ROSC: Return of spontaneous circulation; CPR: Cardiopulmonary resuscitation; PEA: Pulseless electrical activity; VF: Ventricular fibrillation; VT: Ventricular tachycardia

*Pearson Chi-square test

tFisher's Exact test

The frequency of cardiac arrest cases in the emergency room, the extremely valuable time, and the long duration of resuscitations highlight the use of mechanical devices. However, when the situation is evaluated in emergency room conditions, evidence on the effect of mechanical chest compression devices on survival is controversial. In the study of Hayashida et al, it was revealed that mechanical chest compression devices adversely affected ROSC and survival rates [22]. On the other hand, Hock Ong et al stated that the use of loaddistributing band mechanical compression device was associated with better ROSC rates [23].
In our study, ROSC rate was found to be statistically significantly higher in the manual compression group compared to mechanical compression. However, although the 30-day survival and discharge rates were higher in the manual compression group, this difference was not statistically significant. In this study, patients with out-of-hospital cardiac arrest who admitted to the ED when performing CPR were included. The LUCAS-2 device was placed on these patients immediately, and the CPR was continued. In the manual compression group, CPR was continued with a minimum interval by changing hands 
immediately. The interrupted time during this change may have negatively affected the results in the mechanical compression group.

Survival rates obtained in this study were low compared to similar studies, especially in the mechanical compression group $[11,15,17,18]$. Study data did not include prehospital arrest periods for cases. Therefore, the analysis of these prehospital data could not be conducted. Prolonged transfer times may lead to poor survival rates. In this sense, we should state that the prehospital factors in the study could not be standardized. Manual and mechanical compression groups are similar in terms of CPR duration times in the ED. In support of this data, CPR providers' tendency to prolong resuscitation in these two methods can be considered similar in ED settings.

The study being single-centered study, its retrospective design, and the lower number of cases compared to similar studies in the literature are important limitations. CPRs performed at the scene and/or in the ambulance during transfer and the duration time of these outside CPRs were not evaluated. Thus, the prehospital factors in the study could not be standardized. This issue represents an important limitation. In addition, this study did not include data on patients' neurological outcomes.

In summary, no superiority of mechanical chest compression over manual compression was determined in terms of ROSC and survival, and it would not be appropriate to make an unequivocal judgement on the use of this device. However, considering labor loss, we believe that the use of these devices in the ED is rational. There is no clear evidence in the literature regarding this labor gain. Although it is outside the scope of this article, it is believed that these devices are needed in environments such as ambulances and helicopters due to the centrifugal forces that occur in such environments. The discussion of the use of these devices during procedures such as percutaneous coronary intervention is beyond the scope of this article. It is obvious that studies on mechanical chest compression devices will continue; we think that studies on labor loss and economic parameters may help develop a different perspective.

\section{CONFLICTS of INTEREST}

The authors declare no conflict of interest.
[1] Brodal Syversen K, Souvannasacd E, Renger R. Validating the LUCAS $^{\circledR}$ mechanical chest compression fit specifications. Am J Emerg Med. 2019;37(2):371-3. doi: 10.1016/j.ajem.2018.06.069.

[2] Sarıaydın T, Çorbacıoğlu ŞK, Çevik Y, et al. Effect of initial lactate level on short-term survival in patients with out-ofhospital cardiac arrest. Turk J Emerg Med. 2017;17(4):1237. doi: 10.1016/j.tjem.2017.05.003. eCollection 2017 Dec.

[3] Bonnes JL, Brouwer MA, Navarese EP, et al. Manual Cardiopulmonary Resuscitation Versus CPR Including a Mechanical Chest Compression Device in Out-ofHospital Cardiac Arrest: A Comprehensive MetaAnalysis from Randomized and Observational Studies. Ann Emerg Med. 2016;67(3):349-60. doi: 10.1016/j. annemergmed.2015.09.023.

[4] Putzer G, Braun P, Zimmermann A, et al. LUCAS compared to manual cardiopulmonary resuscitation is more effective during helicopter rescue-a prospective, randomized, crossover manikin study. Am J Emerg Med. 2013;31(2):384-9. doi: 10.1016/j.ajem.2012.07.018.

[5] Poole K, Couper K, Smyth MA, et al. Mechanical CPR: Who? When? How? Crit Care. 2018;22(1):140. doi: 10.1186/ s13054-018-2059-0.
[6] Gyory RA, Buchle SE, Rodgers D, et al. The Efficacy of LUCAS in Prehospital Cardiac Arrest Scenarios: A Crossover Mannequin Study. West J Emerg Med. 2017;18(3):437-45. doi: 10.5811/westjem.2017.1.32575.

[7] Rubertsson S, Lindgren E, Smekal D, et al. Mechanical chest compressions and simultaneous defibrillation vs conventional cardiopulmonary resuscitation in out-ofhospital cardiac arrest: the LINC randomized trial. JAMA. 2014;311(1):53-61. doi: 10.1001/jama.2013.282538.

[8] Wik L, Olsen JA, Persse D, et al. Manual vs. integrated automatic load-distributing band CPR with equal survival after out of hospital cardiac arrest. The randomized CIRC trial. Resuscitation. 2014;85(6):741-8. doi: 10.1016/j. resuscitation.2014.03.005.

[9] Brooks SC, Bigham BL, Moririson LJ. Mechanical versus manual chest compressions for cardiac arrest. Cochrane Database Syst Rev. 2011;1:CD007260. doi: 10.1002/14651858.CD007260.pub2.

[10] Brooks SC, Hassan N, Bighm BL, et al. Mechanical versus manual chest compressions for cardiac arrest. Cochrane Database Syst Rev. 2014;2:CD007260. doi: 10.1002/14651858.CD007260.pub3. 
[11] Smekal D, Johansson J, Huzevka T, et al. A pilot study of mechanical chest compressions with LUCAS device in cardiopulmonary resuscitation. Resuscitation. 2011; 82:702-6. doi: 10.1016/j.resuscitation.2011.01.032.

[12] Gates S, Quinn T, Deakin CD, et al. Mechanical chest compression for out-of-hospital cardiac arrest: systematic review and meta-analysis. Resuscitation. 2015; 94:91-7. doi: 10.1016/j.resuscitation.2015.07.002.

[13] Neumar RW, Otto CW, Link MS, et al. Part 8: adult advanced cardiovascular life support: 2010 American Heart Association Guidelines for Cardiopulmonary Resuscitation and Emergency Cardiovascular Care. 2010;122(18 Suppl 3):729-67. doi: 10.1161/CIRCULATIONAHA.110.970988.

[14] Travers AH, Rea TD, Bobrow BJ, et al. Part 4: CPR overview: 2010 American Heart Association Guidelines for Cardiopulmonary Resuscitation and Emergency Cardiovascular Care. 2010;122(18 Suppl 3):676-84. doi: 10.1161/CIRCULATIONAHA.110.970913.

[15] Newberry R, Redman T, Ross E, et al. No Benefit in Neurologic Outcomes of Survivors of Out-ofHospital Cardiac Arrest with Mechanical Compression Device. Prehosp Emerg Care. 2018;22(3):338-44. doi: 10.1080/10903127.2017.1394405.

[16] Wang PL, Brooks SC. Mechanical versus manual chest compressions for cardiac arrest. Cochrane Database Syst Rev. 2018;8:CD007260. doi: 10.1002/14651858.CD007260. pub4.

[17] Hallstrom A, Rea TD, Sayre MR, et al. Manual chest compression vs use of an automated chest compression device during resuscitation following out-of-hospital cardiacarrest:a randomized trial.JAMA. 2006;295(22):26208. doi: 10.1001/jama.295.22.2620
[18] Perkins GD, Lall R, Quinn T, et al. Mechanical versus manual chest compression for out-of-hospital cardiac arrest (PARAMEDIC): a pragmatic, cluster randomized controlled trial. Lancet. 2015;385(9972):947-55. doi: 10.1016/S01406736(14)61886-9.

[19] Lyon RM, Crawford A, Crookston C, et al. The combined use of mechanical CPR and a carry sheet to maintain quality resuscitation in out-of-hospital cardiac arrest patients during extrication and transport. Resuscitation. 2015; 93:102-6. doi: 10.1016/j.resuscitation.2015.05.030.

[20] Cheskes S, Byers A, Zhan C, et al. CPR quality during outof-hospital cardiac arrest transport. Resuscitation. 2017; 114:34-9. doi: 10.1016/j.resuscitation.2017.02.016.

[21] Roosa JR, Vadeboncoeur TF, Dommer PB, et al. CPR variability during ground ambulance transport of patients in cardiac arrest. Resuscitation. 2013;84(5):592-5. doi: 10.1016/j.resuscitation.2012.07.042.

[22] Hayashida K, Tagami T, Fukuda T, et al. Mechanical Cardiopulmonary Resuscitation and Hospital Survival Among Adult Patients with Nontraumatic Out-of-Hospital Cardiac Arrest Attending the Emergency Department: A Prospective, Multicenter, Observational Study in Japan (SOS-KANTO (Survey of Survivors after Out-of-Hospital Cardiac Arrest in Kanto Area) 2012 Study). J Am Heart Assoc. 2017;6(11). pii: e007420. doi: 10.1161/JAHA.117.007420.

[23] Hock Ong ME, Fook-Chong S, Annathurai A, et al. Improved neurologically intact survival with the use of an automated, load-distributing band chest compression device for cardiac arrest presenting to the emergency department. Crit Care. 2012;16(4): R144. doi: 10.1186/ cc11456. 